\title{
THE PRICE SENSITIVITY OF MEDICARE BENEFICIARIES: A REGRESSION DISCONTINUITY APPROACH
}

\author{
THOMAS C. BUCHMUELLER ${ }^{\mathrm{a}, \mathrm{b}, *}$, KYLE GRAZIER $^{\mathrm{b}}$, RICHARD A. HIRTH $^{\mathrm{b}}$ and EDWARD N. OKEKE \\ ${ }^{\mathrm{a}}$ Ross School of Business, University of Michigan, Ann Arbor, MI, USA \\ ${ }^{\mathrm{b}}$ Department of Health Management and Policy, University of Michigan, Ann Arbor, MI, USA \\ ${ }^{\mathrm{c}}$ Department of Global Health and Development, London School of Hygiene and Tropical Medicine, London, UK
}

\begin{abstract}
We use 4 years of data from the retiree health benefits program of the University of Michigan to estimate the effect of price on the health plan choices of Medicare beneficiaries. During the period of our analysis, changes in the University's premium contribution rules led to substantial price changes. A key feature of this 'natural experiment' is that individuals who had retired before a certain date were exempted from having to pay any premium contributions. This 'grandfathering' creates quasi-experimental variation that is ideal for estimating the effect of price. Using regression discontinuity methods, we compare the plan choices of individuals who retired just after the grandfathering cutoff date and were therefore exposed to significant price changes to the choices of a 'control group' of individuals who retired just before that date and therefore did not experience the price changes. The results indicate a statistically significant effect of price, with a $\$ 10$ increase in monthly premium contributions leading to a 2 to 3 percentage point decrease in a plan's market share. Copyright $\odot 2012$ John Wiley \& Sons, Ltd.
\end{abstract}

Received 21 October 2010; Revised 28 August 2011; Accepted 21 October 2011

KEY WORDS: health insurance; Medicare; managed competition; demand elasticity

For many years, leading healthcare reform proposals have been based on the concept of 'managed competition' (Enthoven, 1993). Under this approach, consumers choose from a menu of health plans offering similar benefits. Although premiums are subsidized by a sponsor-the government in the case of these public policy proposals and employers in existing private sector health benefit programs - the subsidies are set so that consumers choosing more costly plans bear the incremental cost of that decision. The goal of this arrangement is to induce consumers to choose less costly plans and to switch plans when premiums change, which in turn will provide an incentive for health plans to compete more vigorously on price. Price-elastic demand is critical for the success of this strategy.

Variants of the managed competition approach have been adopted in recent policy initiatives and have been embraced by policy makers and analysts across the political spectrum. Consumer choice of health plans is a key element of the recently enacted Federal healthcare reform legislation. Starting in 2014, newly insured individuals will be able to purchase insurance through state-sponsored health insurance exchanges designed according to the principles of managed competition. The Commonwealth Connector, a purchasing pool established as part of the 2006 Massachusetts healthcare reforms, is another notable example of this approach (Kingsdale, 2010).

*Correspondence to: Ross School of Business, University of Michigan, Ann Arbor, MI 48109, USA. E-mail: tbuch@umich.edu 
Managed competition has also been proposed as a model for restructuring Medicare to control the growth of program spending. In the $1990 \mathrm{~s}$, there were several prominent proposals, ${ }^{1}$ and the managed competition approach was a major focus of the National Bipartisan Commission on the Future of Medicare that was established at the end of the decade. Although most of its members supported reforms based on this model, the commission did not achieve the supermajority vote required to make a formal recommendation. ${ }^{2}$ Competition among private insurers is also a central component of the Medicare reform strategy proposed by Representative Paul Ryan (2011).

Although fundamental Medicare reforms have not been enacted, private insurance plans and consumer choice play an increasingly important role in the program. Medicare beneficiaries have had the option of receiving their benefits through a health maintenance organization (HMO) since the mid-1980s, although access to such plans has been limited to certain geographic areas. More recently, the menu of private plan options available to beneficiaries has expanded to include preferred provider organizations (PPOs) and private fee-for-service (FFS) plans. Enrollment in these new types of private plans has grown rapidly. Since 2003, the number of beneficiaries in these plans has nearly doubled from 5.3 million to 10.2 million in March 2009 (Kaiser Family Foundation, 2009). By the end of 2008, nearly one quarter of Medicare beneficiaries received their health care through a private plan (Gold, 2009). Private insurers also play a central role in Medicare's prescription drug program. In Medicare Part D as in the standard model of managed competition, consumers choose from a menu of private insurance options and bear the incremental cost of choosing a more costly plan (Neuman and Cubanski, 2009). In light of these public policy developments, there is great interest among health policy analysts in the health plan choices of elderly consumers and, in particular, the effect of price on those choices.

This article analyzes a unique natural experiment to provide new evidence on this issue. We use 4 years of data from the health benefits program of the University of Michigan (UM) to estimate the effect of price on the health plan choices of Medicare-eligible retirees. The analysis exploits quasi-experimental variation in price caused by two important changes in the UM's benefits policies that occurred during the period we analyzed. First, changes in the UM's premium contribution rules dramatically increased the price of the plan that had the greatest enrollment among retirees. This price increase is similar to the variation that is the basis of elasticity estimates produced by prior studies on health plan choice in a managed competition setting (Buchmueller and Feldstein, 1997; Cutler and Reber, 1998; Buchmueller, 2000; Strombom et al., 2002).

It is the second policy change that makes the natural experiment we analyze unique and which allows for a stronger identification of the effect of price on plan choice. At the same time that the UM changed its contribution rules, it decided that individuals who retired before a certain date would be exempted from having to pay any premium contributions for their health insurance. Hence, although at the start of our analysis period all retirees faced the same prices, by the end of the period there was a dramatic difference in premiums between people who retired before and after the cutoff date. Further, this cutoff date was chosen retroactively by more than a decade, alleviating concerns that the change in policy may have influenced decisions to retire before the cutoff.

The sharp discontinuity in prices caused by the UM's 'grandfathering' policy allows for stronger econometric identification than the research design used in most prior studies. We use regression discontinuity techniques to compare the plan choices of people who retired just after the cutoff date, and therefore faced significant price changes, to a control group of otherwise similar retirees who retired just before this date, for whom price was not a factor at all. This comparison allows us to isolate the effect of price, effectively controlling for unobserved plan characteristics that may be correlated with premiums and unobserved individual characteristics that may affect plan choices.

We find a statistically significant effect of price on health plan choice. Although very small changes in price have no discernible effect on plan choice decisions, larger price increases led to a significant reduction in plan

\footnotetext{
${ }^{1}$ See, for example, Enthoven (1988), Aaron and Reischauer (1995), Butler and Moffit (1995), and Dowd et al. (1996).

${ }^{2}$ Available at http://thomas.loc.gov/medicare/mtg31599.html, accessed on July 21, 2010.
} 
market share. Our estimates imply that, ceteris paribus, a $\$ 10$ increase in monthly premium contributions (relative to a $\$ 56$ average out-of-pocket premium difference between the highest and the lowest cost options) will lead to a 2 to 3 percentage point decrease in a plan's market share. This estimate of the marginal effect of price and the corresponding price elasticities are close to estimates generated by previous studies.

\section{PREVIOUS LITERATURE}

Estimating the effect of price on health plan choice decisions requires detailed data on the choice set facing individual consumers, including the exact prices for each choice alternative. Perhaps the best source of such data is the administrative files of large employer-sponsored health benefits programs. One concern with research on the basis of such data is external validity. Even if a study exploits variation in price that is plausibly exogenous, the results may still be sensitive to specific features of the program analyzed and therefore may not generalize to other settings. As a result, there is a benefit to having multiple studies using data from different sources and different identification strategies.

Several studies analyze the effect of premium contributions on the health plan choices of active employees who are offered a choice of health plans (Feldman et al., 1989; Dowd and Feldman, 1994; Buchmueller and Feldstein, 1997; Cutler and Reber, 1998; Royalty and Solomon, 1999; Strombom et al., 2002; Naessens et al., 2008). A consistent finding from this literature is that employees are quite sensitive to price and are willing to switch plans in response to relatively small differences in premiums. In the studies that explicitly calculate them, elasticities of plan choice with respect to the employee's out-of-pocket premium-that is, the 'enrollee-perspective' elasticity—are generally in the range of -0.2 to -0.8 . Because the enrollee's out-of-pocket premium represents only a small portion of the total premium, taking the insurer perspective-that is, calculating the elasticity of plan choice with respect to the total premium-yields much higher elasticities. These elasticities range from -1 to -8 .

Analyses that allow the effect of price to vary with age and health risk indicate that older employees and individuals with greater expected healthcare use are considerably less price sensitive than their younger, healthier counterparts (Royalty and Solomon, 1999; Strombom et al., 2002; Naessens et al., 2008). These patterns raise a concern that research based on working adults may not generalize well to Medicare beneficiaries. There has been less research on the price sensitivity of this population.

Two prior studies use data on retirees that are similar in important ways to ours. Buchmueller (2000) analyzes the plan choices of retirees from the University of California (UC) after the UC adopted a fixed dollar contribution policy, which caused out-of-pocket premium contributions to increase for some plans but not others. Regression estimates for retirees imply that a $\$ 10$ increase in monthly premium contribution led to a 1.3 percentage point decline in plan enrollment. A key limitation of this analysis is that the main source of price variation is across plan types (i.e. FFS versus HMO) and affected all retirees in the same way. Thus, estimates of price sensitivity may be confounded by consumer preferences for other plan attributes or by changes in those attributes occurring at the same time as the price change.

A second study by Buchmueller (2006) uses data from another employer-sponsored program in which premium contributions for retirees are determined by the date an individual retired and his or her years of service at that time. As in our UM data, the rules of the program create essentially random within-plan variation in prices, which is ideal for estimating price effects. The results suggest a slightly more elastic demand than what was found for UC retirees, although the estimated elasticities are smaller in absolute value than what most studies have found for active employees. One limitation of this study is that the sample analyzed is relatively young and includes both Medicare-eligible retirees and retirees 65 years and younger. Employer-sponsored insurance plans, because of the way they interact with Medicare, provide different benefits for these two groups. As a result, elasticity estimates for a mixed sample may be confounded by changes in plan enrollment occurring when an individual qualifies for Medicare. Even if this were not an issue, there remains a question of how well results for younger Medicare beneficiaries generalize to older beneficiaries. 


\section{DATA AND DESCRIPTIVE ANALYSIS}

\subsection{Data source and sample construction}

Our analysis includes retirees from all three UM campuses (Ann Arbor, Dearborn, and Flint) and covers the years 2002 to 2005. Over this period, the UM provided health benefits to more than 5000 retirees, of whom more than 4000 were Medicare beneficiaries. The menu of plans available to these retirees resembles the options currently available to Medicare beneficiaries more generally. The choice set included, in various years, three different HMOs, a point-of-service (POS) plan, two FFS plans, and two PPOs. Provider networks and plan generosity were stable during this period aside from some modest increases in co-payments and deductibles. Plan choices are made during an annual open enrollment period that takes place in the fall, with the choices being effective for the following calendar year.

Because our interest is in understanding the price sensitivity of Medicare beneficiaries, we exclude from the analysis 1093 retirees under age 65 as well 294 retirees with covered spouses not yet eligible for Medicare or with dependent children. Because the data extract was formed on the basis of individuals who were in the benefits system in 2007, we do not have data on retirees who were enrolled in the early years and subsequently died and left the system. However, this selection is likely to be of negligible importance because the surviving spouses of UM retirees retain eligibility for health benefits. Hence, the family units will remain in the sample, although their characteristics can change. These sample selection criteria result in a sample of 3182 individuals per year. Individuals who retired from academic positions (e.g. faculty and academic staff) represent roughly one quarter of this sample (813 individuals).

\subsection{Plan prices and enrollment}

As noted, our identification strategy exploits changes in UM's policies that generated quasi-experimental variation in plan premiums. The effect of these various policy changes on the prices faced by retirees can be seen in Table I, which presents the monthly premium contribution for each plan in each year. In the first 2 years of our data, the UM's contribution toward retiree coverage was set at the premium of the plan with the greatest enrollment, a major medical plan offered by the Blue Cross/Blue Shield of Michigan in conjunction with United Health Care (for brevity, we will refer to this plan as BCMM). In 2002, more than $70 \%$ of UM retirees were in this plan. BCMM enrollees were not required to make monthly premium contributions, whereas those

Table I. Plan offerings and required contributions, 2002-2005

\begin{tabular}{|c|c|c|c|c|c|}
\hline & & 2002 & 2003 & 2004 & 2005 \\
\hline \multirow[t]{2}{*}{ Blue Cross Major Medical } & Single coverage & 0.00 & 0.00 & 16.30 & 42.60 \\
\hline & Two-party coverage & 0.00 & 0.00 & 32.50 & 130.50 \\
\hline \multirow[t]{2}{*}{ Blue Cross PPO } & Single coverage & NA & NA & NA & 0.00 \\
\hline & Two-party coverage & NA & NA & NA & 43.40 \\
\hline \multirow[t]{2}{*}{ MCare HMO } & Single coverage & 29.50 & 0.00 & 14.10 & 13.10 \\
\hline & Two-party coverage & 65.50 & 0.00 & 28.20 & 71.40 \\
\hline \multirow[t]{2}{*}{ MCare POS } & Single coverage & 54.60 & 0.00 & 14.10 & 15.90 \\
\hline & Two-party coverage & 115.70 & 0.00 & 28.20 & 77.20 \\
\hline \multirow[t]{2}{*}{ MCare PPO } & Single coverage & NA & NA & NA & 31.30 \\
\hline & Two-party coverage & NA & NA & NA & 107.90 \\
\hline \multirow[t]{2}{*}{ Care Choices HMO } & Single coverage & 38.40 & 8.30 & 14.60 & 22.10 \\
\hline & Two-party coverage & 83.20 & 16.50 & 29.30 & 89.50 \\
\hline \multirow[t]{2}{*}{ HAP HMO } & Single coverage & 114.80 & 15.60 & 14.80 & 15.90 \\
\hline & Two-party coverage & 236.00 & 31.10 & 29.50 & 77.10 \\
\hline \multirow[t]{2}{*}{ Comprehensive Major Medical } & Single coverage & NA & NA & 15.20 & 20.60 \\
\hline & Two-party coverage & NA & NA & 30.40 & 86.60 \\
\hline
\end{tabular}

Contributions listed for 2002 and 2003 applied to all retirees. In 2004 and 2005, contribution amounts applied only to individuals who retired on or after January 1, 1987. Individuals retiring before this date could choose any plan without paying a monthly contribution. 
choosing a more costly plan paid the difference between that plan's premium and the BCMM premium. The single coverage contributions for the other plans ranged from $\$ 30$ to $\$ 115$ per month.

Starting in 2003, UM 'carved-out' prescription drug benefits. Because prescription drug spending was not distributed equally across plans, this change affected plan premiums and enrollee premium contributions. ${ }^{3}$ As a result of this change, the required contributions for all plans besides BCMM decreased, whereas BCMM remained free for retirees.

The next year, UM changed its premium contribution policy to one where it paid $95 \%$ of the cost of the plan chosen by employees or retirees. ${ }^{4}$ At that time, it was decided that individuals who had retired before January 1 , 1987, would not be required to pay any premium contributions, regardless of the plan they chose. This date was chosen for legal reasons rather than for anything to do with the retirement or plan choice decisions of UM retirees. ${ }^{5}$ Given this motivation and the retrospective nature of this decision, it is reasonable to assume that the price variation generated by this policy is exogenous to retiree preferences or other unmeasured factors that might influence plan choice decisions. The distribution of retirement dates, presented in Figure A1, supports this assumption. Figure A1 plots the number of retirements by quarter for a 4-year period bracketing the January 1, 1987, cutoff date. We reported the data separately for academic and nonacademic positions because faculty retirements tend to occur at the end of the academic year, whereas retirements by nonacademics do not exhibit such a strong seasonal pattern. Apart from this difference, there is no obvious pattern in the data. The number of nonacademics retiring in the last quarter of 1986 is slightly lower than the number retiring in the first quarter of 1987. This is the opposite of what we would see if individuals were rushing to retire to qualify for more generous benefits.

The combination of the change in the contribution policy and the grandfathering decision meant that in 2004 out-of-pocket prices for pre- and post-1987 retirees began to diverge. The small contributions that were required in 2003 were eliminated for pre-1987 retirees. For individuals who had retired after January 1, 1987, enrollment in BCMM now required a monthly premium contribution of $\$ 16.30$ for single coverage and $\$ 32.50$ for family coverage. BCMM was no longer the lowest cost option for retirees, although the difference between it and less expensive plans was very small-approximately $\$ 1$ or $\$ 2$ per month for single coverage.

UM altered its contribution policy more significantly in 2005. Under the new policy, UM's contribution toward single coverage was set equal to $95 \%$ of the average premium for the two lowest cost plans on the menu, and the contribution for dependent coverage was set so that in aggregate the UM paid $85 \%$ of the average premium. Employees and retirees who chose more expensive plans now had to pay the full difference between the plan's premium and the fixed UM contribution. The combination of this change plus differential trends in total plan premiums meant that BCMM, which only 2 years before had been the low cost plan on the menu, was now the most expensive option, with a monthly contribution of $\$ 42.60$ for single coverage and $\$ 130.00$ for two-party (i.e. retiree plus spouse) coverage.

Table II presents the distribution of plan choices for the period of our analysis. The top panel presents data for all retirees with Medicare coverage; in the second and third panels, we cut the data by retirement age, differentiating our 'control group' of pre-1987 retirees and our 'treatment group' consisting of individuals retiring on or after January 1, 1987. In 2002, approximately $70 \%$ of all Medicare-eligible retirees were enrolled in BCMM. BCMM was chosen by a higher share of retirees in the control group than in the treatment group. Most of this difference is driven by higher likelihood that the control group had moved away from the Ann

\footnotetext{
${ }^{3}$ Under the carve out, coverage (e.g. preferred formularies) and co-payments for prescription drugs do not vary across plans. Plan premiums are set to reflect the vendor's cost for medical coverage plus the uniform (across plan options) average self-insured cost of the prescription coverage.

${ }^{4}$ Details of the 2004 policy change and its effect on premiums for active employees are described by Okeke et al. (2010a).

${ }^{5}$ When they began considering altering the contribution policy, human resources administrators were concerned about the potential perception that the UM was reneging on an implicit contract with existing retirees. A review of benefits materials and related communications with employees and retirees indicated that since at least 1988 , these materials had explicitly stated that the UM retained the right to alter its policy on plan premium contributions and consequently retirees could at some point be required to pay more for their coverage.
} 
Table II. Distribution of plan choices by year

\begin{tabular}{|c|c|c|c|c|}
\hline & 2002 & 2003 & 2004 & 2005 \\
\hline \multicolumn{5}{|l|}{ Full sample $(N=3182)$} \\
\hline Blue Cross Major Medical & $69.9 \%$ & $69.9 \%$ & $69.4 \%$ & $57.8 \%$ \\
\hline Blue Cross PPO & - & - & - & 12.6 \\
\hline MCare HMO & 19.0 & 17.1 & 16.3 & 15.6 \\
\hline MCare POS/PPO & 3.2 & 5.1 & 5.4 & 5.4 \\
\hline Other Plans & 7.9 & 8.0 & 8.2 & 7.9 \\
\hline Waived Coverage & 0.0 & 0.0 & 0.6 & 0.7 \\
\hline \multicolumn{5}{|c|}{ Retired before January 1, $1987(n=1123)$} \\
\hline Blue Cross Major Medical & $83.1 \%$ & $82.6 \%$ & $82.8 \%$ & $80.7 \%$ \\
\hline Blue Cross PPO & - & - & - & 2.0 \\
\hline MCare HMO & 11.8 & 11.1 & 10.7 & 10.2 \\
\hline MCare POS/PPO & 1.1 & 2.1 & 2.1 & 2.7 \\
\hline Other Plans & 4.0 & 4.1 & 4.3 & 4.5 \\
\hline Waived Coverage & 0.0 & 0.0 & 0.0 & 0.0 \\
\hline \multicolumn{5}{|c|}{ Retired after January 1, $1987(n=2059)$} \\
\hline Blue Cross Major Medical & $62.7 \%$ & $62.9 \%$ & $62.1 \%$ & $45.4 \%$ \\
\hline Blue Cross PPO & - & & & 18.4 \\
\hline MCare HMO & 23.0 & 20.4 & 19.4 & 18.5 \\
\hline MCare POS/PPO & 4.4 & 6.7 & 7.2 & 7.0 \\
\hline Other plans & 10.0 & 10.0 & 10.4 & 9.7 \\
\hline Waived Coverage & 0.0 & 0.1 & 0.9 & 1.1 \\
\hline
\end{tabular}

Arbor area, and once this and other characteristics are accounted for, retirement date no longer predicts plan choice (see Table VI). The second most popular plan (MCare HMO) enrolled 19\% of the full sample. MCare also offered a POS plan that enrolled 3.3\% of all UM retirees. Because the market shares for the remaining plans were all in the low single digits, we grouped these plans together.

As noted, premium contributions for the HMOs between 2002 and 2003 fell, although these plans were still more expensive than BCMM. The values presented in Table II show that the HMOs did not gain market share because of the change in relative prices. Similarly, the small price changes that occurred between 2003 and

Table III. Regression discontinuity results

\begin{tabular}{|c|c|c|c|c|c|}
\hline & (1) & (2) & (3) & (4) & (5) \\
\hline \multicolumn{6}{|l|}{ Dependent variable } \\
\hline 1. $\mathrm{BCMM}_{2002}$ & $\begin{array}{c}-0.024 \\
(0.040)\end{array}$ & $\begin{array}{c}-0.005 \\
(0.039)\end{array}$ & $\begin{array}{c}-0.026 \\
(0.064)\end{array}$ & $\begin{array}{c}0.027 \\
(0.059)\end{array}$ & $\begin{array}{c}0.031 \\
(0.060)\end{array}$ \\
\hline 2. $\mathrm{BCMM}_{2003}$ & $\begin{array}{c}-0.015 \\
(0.041)\end{array}$ & $\begin{array}{c}0.003 \\
(0.039)\end{array}$ & $\begin{array}{c}0.035 \\
(0.064)\end{array}$ & $\begin{array}{c}0.036 \\
(0.060)\end{array}$ & $\begin{array}{c}0.045 \\
(0.070)\end{array}$ \\
\hline 3. $\mathrm{BCMM}_{2004}$ & $\begin{array}{c}-0.039 \\
(0.042)\end{array}$ & $\begin{array}{c}-0.021 \\
(0.040)\end{array}$ & $\begin{array}{c}0.007 \\
(0.066)\end{array}$ & $\begin{array}{c}0.008 \\
(0.040)\end{array}$ & $\begin{array}{c}0.012 \\
(0.070)\end{array}$ \\
\hline 4. $\mathrm{BCMM}_{2005}$ & $\begin{array}{c}-0.160 \\
(0.044) *\end{array}$ & $\begin{array}{c}-0.141 \\
(0.043) *\end{array}$ & $\begin{array}{c}-0.175 \\
(0.072)^{*}\end{array}$ & $\begin{array}{c}-0.177 \\
(0.068) *\end{array}$ & $\begin{array}{c}-0.180 \\
(0.076)^{*}\end{array}$ \\
\hline 5. $\mathrm{BCMM}_{2005}-\mathrm{BCMM}_{2002}$ & $\begin{array}{c}-0.137 \\
(0.032) *\end{array}$ & $\begin{array}{c}-0.136 \\
(0.032)^{*}\end{array}$ & $\begin{array}{c}-0.200 \\
(0.049)^{*}\end{array}$ & $\begin{array}{c}-0.204 \\
(0.049)^{*}\end{array}$ & $\begin{array}{c}-0.211 \\
(0.053)^{*}\end{array}$ \\
\hline Sample of retirees & All & All & \pm 5 years from $1 / 87$ & \pm 5 years from $1 / 87$ & All \\
\hline Specification of $R$ & Quartic & Quartic & Quartic & Quartic & Local polynomial \\
\hline Covariates & No & Yes & No & Yes & No \\
\hline No. observations & 3182 & 3182 & 1467 & 1467 & 3182 \\
\hline
\end{tabular}

Each row represents separate regressions of BCMM enrollment in a particular year as a function of retirement date $(R)$. The covariates in columns 2 and 4 are gender, marital status, surviving spouse status, residential location (dummies for living in Ann Arbor and living out of state), and mean income in the person's zip code. The local polynomial regressions use a bandwidth of 2 . Standard errors (robust in columns $1-4$, bootstrapped in column 5) are in parentheses.

*Significant at the 0.05 level. 
2004 did not shift enrollment. In contrast, it seems that the increase in BCMM's price between 2004 and 2005 did lead to a significant decline in that plan's market share. In the full sample, BCMM enrollment declined by roughly 12 percentage points. The data in the lower two panels of Table III show that this decline was almost entirely driven by the retirees who faced a price increase. Among post-1987 retirees, BCMM enrollment fell by 16.7 points, compared with a decline of 1.9 percentage points for pre-1987 retirees. Most of the retirees who left the BCMM plan switched to the less costly PPO that Blue Cross began offering that year. The market share of other plans on the menu changed only slightly.

\section{ECONOMETRIC ANALYSIS}

\subsection{Regression discontinuity results}

The difference in the way that enrollment patters changed over time for pre- and post-1987 retirees suggests a negative effect of price on health plan choice. The obvious problem with this comparison is that the two groups are different in several ways. Indeed, in 2002 when the two groups faced the same prices, pre-1987 retirees were 20 percentage points more likely to be enrolled in BCMM. This problem of heterogeneity can be minimized, however, if we limit the comparison to individuals who retired just before and just after January 1, 1987. Even if there is a general relationship between retirement date and plan choice, the stark nature of the grandfathering policy provides a source of clean identification. Because the cutoff date was chosen retroactively in 2004, there is no way that the difference in contribution rules applying to pre- and post-1987 retirees could have affected retirement decisions. As a result, for people who retired near the cutoff date, assignment to the treatment and control groups is essentially random. Therefore, we can use regression discontinuity (RD) techniques to estimate the effect of the price changes that took place in 2004 and 2005.

Because BCMM enrolled such a high percentage of UM retirees over this period and because it seems that it was the price increase for this plan between 2004 and 2005 that induced the strongest demand response, our regression analysis focuses on enrollment in that plan. The main dependent variable we analyzed is a binary variable, $\mathrm{BCMM}_{i t}$, which equals one for individuals enrolled in BCMM in year $t$ and zero for those who enrolled in other plans or chose to waive coverage. ${ }^{6}$ For each year of enrollment data, we estimated the following model:

$$
\mathrm{BCMM}_{i t}=a_{t}+X_{i} \beta_{t}+\left(1-T_{i}\right) \times g_{1 t}\left(R_{i}\right)+\delta_{t} T_{i}+T_{i} \times g_{2 t}\left(R_{i}\right)+u_{i t}
$$

The binary variable $T$ identifies members of the treatment group who retired after January 1,$1987 ; R_{i}$ is an integer corresponding to the exact date of retirement, and $g_{1 t}($.$) and g_{2 t}($.$) are flexible functions of R$. In Figures 1 and 2, we reported results from a weighted local polynomial regression (Nichols, 2007). ${ }^{7}$ The estimates of $\delta$ from this specification along with bootstrapped standard errors are reported in the last column of Table III. For the sake of comparison, and to show that our results are not sensitive to functional form, we also reported alternative parametric specifications. In columns 1 and 2 of Table III, we reported results from a model in which the regression is estimated using the full sample of retirees, and $g_{1 t}($.$) and g_{2 t}($.$) are specified as fourth-order$ polynomials of $R$. The model in column 1 does not include covariates. The model in column 2 includes the following: age (in 2002), age squared, gender, zip code level of average income and indicator variables for surviving spouses, individuals with two-party coverage, those living in Ann Arbor, and those living out of state. We repeated these two specifications in columns 3 and 4 while restricting the sample to individuals who retired no more than 5 years before or after January 1, 1987.

\footnotetext{
${ }^{6}$ Our focus on this binary outcome is similar to the approach taken by Cutler and Reber (1998) and Buchmueller (2000). In those studies, as in ours, the main source of price variation was changes in the price of a popular plan, and there was limited price variation among other smaller plans.

${ }^{7}$ The models reported in the figures and column 1 of Table III use a triangular kernel with a bandwidth of 2 . The results are not sensitive to the use of alternative kernels or bandwidths.
} 

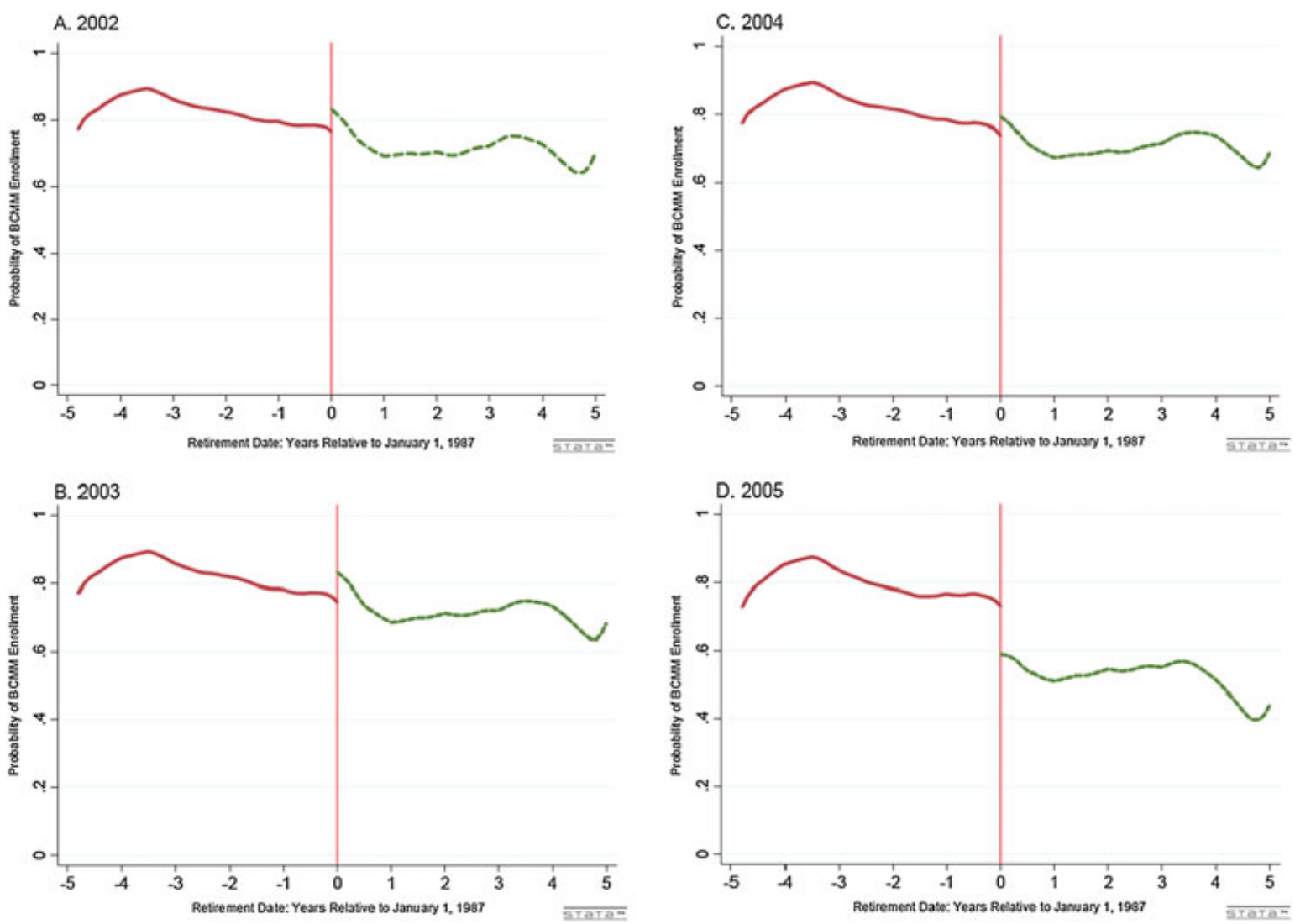

Figure 1. Regression discontinuity estimates, 2002 to 2004

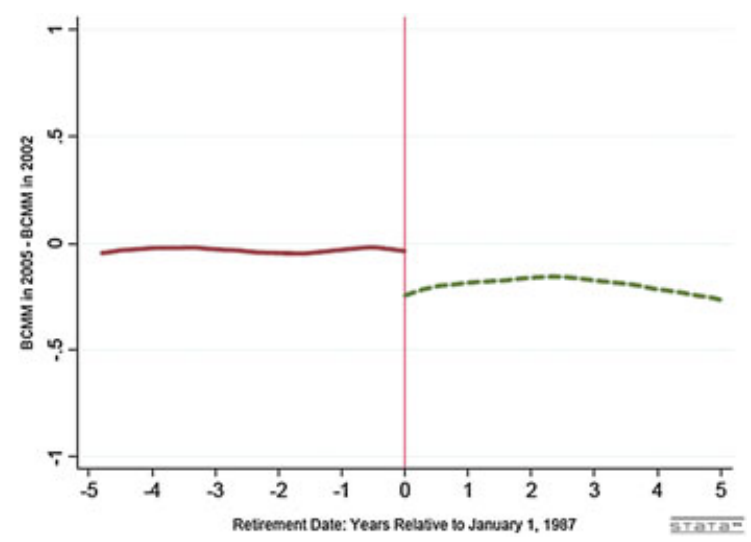

Figure 2. Change in BCMM enrollment, 2005 minus 2002

We begin by estimating the relationship between retirement date and BCMM enrollment in 2002 and 2003. These outcomes provide an important test of the validity of the RD approach for analyzing the effect of price changes that occurred in later years. Because the grandfathering policy was not yet established, in 2002 and 2003 pre- and post-1987 retirees faced the same prices. In other words, for these years, there is no 'treatment', 
which means there is no reason to expect a discontinuity in BCMM enrollment around the retirement date of January 1, 1987. The regression discontinuity results are consistent with this expectation. Panel A of Figure 1 shows that in 2002, individuals who retired in early 1987 were slightly more likely to be in BCMM than those retiring in late $1986 .{ }^{8}$ However, this difference is not significantly different from zero. The point estimate of $\delta$ from the local polynomial regressions is 0.03 , with a bootstrapped standard error of 0.06 . The other two models reported in Table III also indicate that there was no significant difference in BCMM enrollment between our treatment and control groups in 2002. Although the point estimates vary across the samples and specifications, none come close to being statistically significant; the largest absolute $t$-statistic is 0.59 . The plot for 2003 (Figure 1B) is barely distinguishable from the one for 2002, which reflects the fact that the decline in required contributions for the HMOs between 2002 and 2003 did not induce movement out of BCMM.

By 2004, the grandfathering policy was in place, although the difference in prices faced by pre- and post-1987 retirees was small. For pre-1987 retirees, BCMM was free, whereas for post-1987 retirees, the required contribution for BCMM was only a few dollars per month higher than the cost of other plans. The RD results presented in Figure 1C and Table III suggest that this price difference was not enough to affect enrollment decisions. In the local polynomial model, retirement after the cutoff date led to an insignificant $1.2 \%$ increase in the probability of choosing BCMM. The results from the quartic models also indicate no significant difference in BCMM enrollment between the treatment and the control groups.

We do find a larger and statistically significant treatment effect in 2005. Recall that in that year, the price of BCMM for post-1987 retirees increased to $\$ 42.60$ for single coverage and $\$ 130.50$ for two-party coverage. Because the lowest cost options required a $\$ 43$ contribution for two-party coverage, the incremental cost of choosing BCMM was $\$ 87$ for two-party coverage. Weighting these amounts by the percentage of retirees in each coverage tier yields an average price difference between the treatment and the control groups of $\$ 56$ per month. ${ }^{9}$ In Figure 1D, we plotted the relationship between retirement date and BCMM enrollment in 2005. The graph to the left of the grandfathering cutoff date is virtually identical to the plot for the earlier years, indicating that there was very little plan switching among pre-1987 retirees. Just to the right of the grandfathering cutoff date, there is a discrete drop in BCMM enrollment, indicating that the price increase caused some post-1987 retirees to switch out of BCMM.

The three regression specifications reported in Table III imply that the price increase led to a significant decline in BCMM enrollment. The point estimate is slightly larger when we put more weight on people who retired close to the cutoff date. The local polynomial model indicates that the probability of choosing BCMM is 18 percentage points lower for individuals who retired just after the grandfathering cutoff date compared with those who retired just before. The point estimates from the quartic models in columns 3 and 4 are similar: -0.175 when we do not include covariates (column 3 ) and -0.177 when we do (column 4). Dividing these estimates by the difference in the average price for the treatments and controls yields a marginal price effect of -0.003 . In other words, these results imply that a $\$ 10$ increase in monthly premium contributions will reduce the plan's share of total enrollment by 3 percentage points. Below, we discussed the magnitude of these effects in the context of the previous literature.

The effect of the price increase on plan switching can be shown more directly by analyzing the relationship between the retirement date and the change in BCMM enrollment between 2002 and 2005: $\triangle \mathrm{BCMM}=$ $\mathrm{BCMM}_{2005}-\mathrm{BCMM}_{2002} \cdot{ }^{10}$ Analyzing switching allows us to better hold constant time invariant factors, such as individual preferences and nonprice plan attributes, which may affect plan choice decisions. Figure 2 presents the plot of the local polynomial regressions for this outcome. On both sides of the cutoff date, the fitted

\footnotetext{
${ }^{8}$ For visual clarity, we limit the plot to observations with retirement dates no more than 5 years before or after January $1,1987$.

${ }^{9}$ Among individuals retiring no more than 5 years before or after the cutoff date, $69 \%$ have single coverage.

${ }^{10}$ Buchmueller and Feldstein (1997) and Buchmueller (2000) examined the effect of price changes on the decision to switch out of any plan, which they modelled as a binary outcome. In our switching analysis, the dependent variable takes the value of -1 for people who switched from BCMM into one of the other plans, 1 for people who switched into BCMM, and 0 for people who did neither.
} 
Table IV. Sensitivity Tests

\begin{tabular}{|c|c|c|}
\hline & (1) & (2) \\
\hline \multicolumn{3}{|l|}{ (A) Testing for discontinuities in covariates } \\
\hline 1. Age in 2002 & $\begin{array}{c}-0.482 \\
(0.525)\end{array}$ & $\begin{array}{c}-0.742 \\
(0.658)\end{array}$ \\
\hline 2. Male & $\begin{array}{c}-0.047 \\
(0.046)\end{array}$ & $\begin{array}{c}-0.201 \\
(0.079)^{*}\end{array}$ \\
\hline 3. Married in 2002 & $\begin{array}{c}0.015 \\
(0.046)\end{array}$ & $\begin{array}{c}0.030 \\
(0.115)\end{array}$ \\
\hline 4. Surviving spouse in 2002 & $\begin{array}{c}-0.040 \\
(0.028)\end{array}$ & $\begin{array}{c}0.002 \\
(0.049)\end{array}$ \\
\hline 5. Lives in Ann Arbor in 2002 & $\begin{array}{c}0.031 \\
(0.047)\end{array}$ & $\begin{array}{c}-0.072 \\
(0.078)\end{array}$ \\
\hline 6. Lives out of state in 2002 & $\begin{array}{c}-0.043 \\
(0.035)\end{array}$ & $\begin{array}{c}0.021 \\
(0.065)\end{array}$ \\
\hline 7. Average income of 2002 zip code & $\begin{array}{c}1.109 \\
(1.215)\end{array}$ & $\begin{array}{c}-1.687 \\
(2.040)\end{array}$ \\
\hline \multicolumn{3}{|c|}{ (B) Testing for discontinuities in $\mathrm{BCMM}_{2005}$ at other dates } \\
\hline 8. January 1,1985 & $\begin{array}{r}-0.050 \\
(0.171)\end{array}$ & $\begin{array}{r}-0.035 \\
(0.072)\end{array}$ \\
\hline 9. January 1,1989 & $\begin{array}{c}0.032 \\
(0.260)\end{array}$ & $\begin{array}{c}-0.000 \\
(0.092)\end{array}$ \\
\hline
\end{tabular}

Regressions reported in panel A are for the full sample. Those in row 8 of panel B pertain to individuals who retired before January 1,1987 $(n=1111)$, and the estimates in row 9 are for individuals retiring after that date $(n=2054)$. For both panels, the estimates in column 1 are based on separate quartic regressions on either side of the cutoff date. In panel A, there are no covariates. The regressions in column 1 of panel B include the full set of covariates from Table III. The results in column 2 of both panels are from local polynomial regressions (using a bandwidth of 2). Standard errors (robust in column 1, bootstrapped in column 2) are in parentheses.

*Significant at the 0.05 level.

curves are essentially horizontal. In columns $3-5$, the estimated gap between the two curves is approximately 20 percentage points, which is slightly larger than the corresponding cross-sectional result for 2005.

The fact that the fitted regression line is flat to the right of the cutoff date indicates that within the treatment group, the response to the price increase did not vary with retirement date. This finding along with the null results for 2002 and 2003 provides support for the research design. As an additional specification check, we test whether other variables exhibit discontinuities at the grandfathering cutoff date. It is to be expected that pre-1987 retirees are older on average than post-1987 retirees. However, a difference in mean age is not by itself a threat to our research design. On the other hand, we would be concerned if there were a discontinuity in age around the retirement date of January 1, 1987. We test for such a discontinuity in age and other covariates.

Results from these tests are reported in panel A of Table IV. The specifications are the same as those in columns 1 and 5 of Table III. ${ }^{11}$ With one exception, all of the estimated discontinuities are statistically insignificant. That exception is the local polynomial model for the percentage of male retirees, which suggests that men represent a higher proportion of individuals who retired just before January 1, 1987, as compared with those retiring just after that date. A closer inspection of the date suggests that this is not a real discontinuity. In Figure A2, by year of retirement, we plot the percentage of male retirees. Figure A2 shows that this percentage is generally increasing with respect to retirement date, although the graph is fairly jagged. Because the value for $1985(30.7 \%)$ is below the trend line, whereas the value for $1986(48.3 \%)$ is above, the slope of the local polynomial regression is quite steep just to the left of the cutoff. Alternative specifications that put less weight on the data from 1986, such as the other model reported in Table IV, indicate a smaller, statistically insignificant change in the percentage of male retirees around the cutoff date. Similarly, a simple

\footnotetext{
${ }^{11}$ Because there is little correlation among the covariates, adding controls to the quartic model reported in column 2 has no effect on the estimated discontinuity. Therefore, we do not report these models.
} 
Table V. Sample characteristics by date of retirement

\begin{tabular}{lccc}
\hline & All retirees & Retired 1985-1986 & Retired 1987-1988 \\
\hline Age (years) & 74.99 & 77.84 & $76.14^{*}$ \\
Male & 0.42 & 0.40 & 0.41 \\
Married & 0.47 & 0.40 & 0.44 \\
Surviving spouse & 0.09 & 0.14 & $0.08^{*}$ \\
Academic & 0.25 & 0.23 & 0.27 \\
Lives in Ann Arbor & 0.46 & 0.43 & 0.49 \\
Lives out of state & 0.16 & 0.20 & $0.14^{*}$ \\
Zip code average income (\$000) & 42.09 & 36.23 & $40.13^{*}$ \\
Number of observations & 3182 & 369 & 308 \\
\hline
\end{tabular}

*Difference between pre- and post-1987 retirees is significant at the 0.05 level.

comparison of all individuals who retired in the 2 years before and after January 1, 1987, reveals no significant difference between the percentage of male retirees (see Table V). Because of this general pattern and the fact that gender is not a significant predictor of BCMM enrollment (see Table VI), we are confident that our main estimates are not confounded by the gender composition of our treatment and control groups.

As an additional specification test, we estimated the discontinuity in $\mathrm{BCMM}_{2005}$ at retirement dates other than the actual grandfathering cutoff. The results from two such placebo tests are reported in panel B of Table IV. In row 8, we limited the sample to people who retired before January 1987 and estimate the discontinuity at January 1, 1985. In row 9, we conducted a similar exercise on the other side of the cutoff, testing for a discontinuity at January 1, 1989. In both cases, the estimated discontinuities are not significantly different from zero.

\subsection{Estimating the marginal effect of price}

The RD analysis provides strong evidence that the increase in BCMM's price between 2004 and 2005 led to a significant decline in that plan's market share, although the smaller price changes between 2003 and 2004 did not affect plan enrollment. To provide an overall estimate of the effect of price and to facilitate comparisons with estimated price effects from prior studies, we combine the data for all 4 years and estimate the following regression model:

$$
\mathrm{BCMM}_{i t}=X_{i t} \beta+\theta P_{i t}^{B}+\mu_{i}+v_{i t}
$$

The independent variable of primary interest is $P_{i t}^{B}$, the monthly cost of the BCMM plan relative to the lowest cost option on the menu. ${ }^{12}$ As shown in Table I, this price depends on whether or not the policy covers a dependent. In principle, retirees could respond to an increase in price by dropping dependent coverage; in reality, we do not observe such behavior in our data on UM retirees. ${ }^{13}$ Therefore, we assign to each individual the relative BCMM price corresponding to their coverage tier (retiree only or retiree plus spouse).

The error term includes both an individual-specific effect, $\mu_{i}$, and an i.i.d. disturbance, $v_{i t}$. We report regressions from fixed effect specifications, although models that treat $\mu_{i}$ as a random effect yield essentially identical

\footnotetext{
${ }^{12}$ In principle, the relative price of BCMM should be computed with reference to each retiree's next preferred alternative, which is unobserved. In 2005, the prices for all the other plans are all within a dollar of each other, so choosing one or another as the point of comparison or using an average of non-BCMM prices yields essentially the same result. In 2005, the low cost option is the Blue Cross PPO, which is the plan chosen by most of individuals who switched out of BCMM. Thus, there is no reason to expect our results to be sensitive to the construction of the price variable.

${ }^{13}$ In other research, we find that active employees do drop dependent coverage when the incremental cost of that coverage increases (Okeke et al., 2010b). Active employees who drop dependent coverage typically do so when their spouse has the option of coverage through his or her own employer. Spouses of retirees are much less likely to have an alternative source of employer-sponsored coverage. In addition, the university's rules make it difficult to reenroll the spouse of a retiree after dependent coverage has been dropped.
} 
Table VI. Linear probability regression results

\begin{tabular}{|c|c|c|c|}
\hline & Full sample & Retired 1982-1991 & Retired 1985-1989 \\
\hline Price of BCMM & $\begin{array}{l}-0.0023 \\
(0.0002)^{*}\end{array}$ & $\begin{array}{l}-0.0028 \\
(0.0003)^{*}\end{array}$ & $\begin{array}{l}-0.0026 \\
(0.0005)^{*}\end{array}$ \\
\hline Age: 75 to 84 years & $\begin{array}{c}-0.0094 \\
(0.0117)\end{array}$ & $\begin{array}{c}-0.0142 \\
(0.0150)\end{array}$ & $\begin{array}{c}-0.0254 \\
(0.0201)\end{array}$ \\
\hline Age: 85 years and older & $\begin{array}{c}0.0189 \\
(0.0145)\end{array}$ & $\begin{array}{c}0.0262 \\
(0.0188)\end{array}$ & $\begin{array}{c}0.0243 \\
(0.0266)\end{array}$ \\
\hline Lives in Ann Arbor & $\begin{array}{c}-0.0571 \\
(0.0307)\end{array}$ & $\begin{array}{c}-0.0521 \\
(0.0372)\end{array}$ & $\begin{array}{c}-0.1321 \\
(0.0635)^{*}\end{array}$ \\
\hline Lives out of state & $\begin{array}{c}0.0961 * \\
(0.0407)^{*}\end{array}$ & $\begin{array}{c}0.0585 \\
(0.0459)\end{array}$ & $\begin{array}{c}-0.0008 \\
(0.0037)\end{array}$ \\
\hline Two-party coverage & $\begin{array}{c}0.0502 \\
(0.0329)\end{array}$ & $\begin{array}{c}0.0323 \\
(0.0447)\end{array}$ & $\begin{array}{c}0.0078 \\
(0.0602)\end{array}$ \\
\hline Year $=2003$ & $\begin{array}{c}-0.0019 \\
(0.0022)\end{array}$ & $\begin{array}{c}-0.0030 \\
(0.0028)\end{array}$ & $\begin{array}{c}-0.0075^{*} \\
(0.0037)^{*}\end{array}$ \\
\hline Year $=2004$ & $\begin{array}{c}-0.0009 \\
(0.0033)\end{array}$ & $\begin{array}{c}-0.0059 \\
(0.0041)\end{array}$ & $\begin{array}{c}-0.0144 \\
(0.0063)^{*}\end{array}$ \\
\hline Year $=2005$ & $\begin{array}{c}-0.0342 \\
(0.0070)^{*}\end{array}$ & $\begin{array}{c}-0.0336 \\
(0.0086)^{*}\end{array}$ & $\begin{array}{c}-0.0434 \\
(0.0130)^{*}\end{array}$ \\
\hline Number of observations & 12,644 & 5840 & 2700 \\
\hline Number of individuals & 3161 & 1460 & 675 \\
\hline
\end{tabular}

Results are from a fixed effects model. The dependent variable equals one for individuals enrolled in BCMM and zero otherwise. Robust standard errors (clustered by retiree) are in parentheses.

*Significant at the 0.05 level.

estimates of $\theta$. This is not surprising given the nature of our price variation. In addition to reporting results for the full sample of UM retirees, we also report estimates for subsamples who retired within different windows around January 1, 1987. The logic for restricting the sample in this way is the same as that behind the regression discontinuity models. Although more recent cohorts of retirees may make different health plan choices than earlier cohorts, there is no reason to think that individuals who retired just before this date are different in ways that affect their demand for health insurance than individuals who retired just after this date.

Table V presents the summary statistics for the full sample of retirees and for the treatment and control groups defined according to a window of plus or minus 2 years. To give a fuller sense of how the samples compare, Table V presents time-invariant variables that drop out of the fixed effect model. As would be expected, individuals who retired between 1985 and 1988 are slightly older than the full sample of UM retirees, and those who retired in 1985-1986 are slightly older than those who retired in 1987-1988. Other differences between the treatment and the control groups relate to where they live: pre-1987 retirees are more likely to have moved out of state and less likely to live in Ann Arbor. Because of these location decisions, pre-1987 retirees live in areas with lower average incomes. ${ }^{14}$

The main regression results are reported in Table VI. The results in the first column are for the full sample of retirees. In column 2, we restrict the sample to individuals who retired no more than 5 years before or after the grandfathering cutoff date. In column 3, we tighten the focus to 2 years on either side of that date. The estimated price coefficients for the three samples are essentially identical. All three imply that a $\$ 10$ increase in monthly premium contributions will lead to a reduction in plan market share of between two and three percentage points.

Note that this price effect is slightly smaller than the one implied by the RD analysis of the 2005 data. The reason is that it essentially averages that effect with the zero effect of the much smaller price increase that occurred between 2003 and 2004. The magnitude of this overall effect is similar to that found in prior studies. The most comparable study is Buchmueller's (2000) analysis of data on UC retirees in the 1990s. The parameter

\footnotetext{
${ }^{14}$ The income variable is formed by assigning each individual the ZIP code-level mean income from the 2000 Decennial Census based on their ZIP code of residence in 2002. This crude measure is intended to capture cross-sectional differences in income among retirees. As such, we did not recode this variable for individuals who moved during the period of our analysis.
} 
Table VII. Estimated premium elasticities

\begin{tabular}{lccccc}
\hline & Full sample & Single coverage & Two-Party coverage & Academic & Nonacademic \\
\hline Marginal price effect & -0.0023 & -0.0021 & -0.0023 & -0.0024 & -0.0024 \\
& $(0.0002)$ & $(0.0003)$ & $(0.0002)$ & $(0.0003)$ & $(0.0002)$ \\
& & & & -0.045 & -0.033 \\
Enrollee-perspective elasticity & & & -0.045 & -0.061 \\
$\quad$ At sample mean for all retirees & -0.034 & -0.021 & -0.069 & -0.069 & -1.52 \\
At sample means for post-1987 retirees & -0.060 & -0.041 & & -1.71 & -1.75 \\
Insurer-perspective elasticity & & & -2.02 & 3236 & 9408 \\
$\quad$ At sample means for all retirees & -1.47 & -0.98 & -2.20 & & \\
$\quad$ At sample means for post-1987 retirees & -1.73 & -1.14 & & & \\
Number of observations & 12,644 & 8399 & & & \\
\hline
\end{tabular}

The estimation samples for these results are not limited by retirement date.

estimates from that study imply that a $\$ 10$ increase in monthly premium contributions would cause a plan's enrollment to decline by between 1 and 2.5 percentage points, depending on the estimation sample analyzed. After accounting for inflation, our estimates fall squarely in the center of that range. Our estimated price effects are slightly smaller in magnitude than the estimates from the other study by Buchmueller (2006), who used data on retirees from a private company.

In Table VII, we report alternative elasticity estimates for the full sample as well as for different subsamples of interest. Expressing marginal price effects as elasticities can be sensitive to the point at which the function is evaluated. Because premium contributions were fixed at zero for the control group and started at zero for the treatment group, the mean price for BCMM in the full estimation sample is fairly low: $\$ 9.90$ per month. Using this value along with the full sample mean for BCMM's market share yields an 'enrollee-perspective' elasticity of -0.034 . When we evaluate the elasticity function at the mean price and market share for our treatment group, the price elasticity is -0.06 . These are smaller in absolute value than the estimated elasticities from the two comparable prior studies (Buchmueller, 2000, 2006). However, this difference is driven by the fact that the mean premium contribution was higher and the mean market share was lower in those data sets. ${ }^{15}$

In columns 2 and 3 of Table VII, we report results from models estimated separately by coverage tier-single coverage and two-party coverage. The point estimates of the marginal price effect are nearly identical for these two groups. Because premium contributions are higher for two-party coverage, the implied elasticity is slightly higher for this group, although the difference is not economically meaningful.

One potential criticism of studies that use data on UM employees is that highly educated academics are not representative of employees and retirees more generally. Although the fact that faculty and academic staff represent only approximately one quarter of the retirees in our sample mitigates this concern, it is useful to test whether individuals who retired from academic positions are different from nonacademic retirees. The last two columns of Table VII show that the results are not sensitive to this stratification. The fixed effect specification yields identical estimates of the price coefficient for these two groups.

It is common in the literature to calculate 'insurer-perspective' elasticities by evaluating the elasticity function at the full premium charged by a health plan rather than at the subsidized price faced by enrollees. The lower panel of Table VII reports such estimates. In 2005, the full premium for the BCMM plan was $\$ 318$ per month for retirees with Medicare choosing single coverage and \$636 for retirees choosing two-party coverage. Because $66 \%$ of UM retirees in the full sample chose single coverage, these values translate to an average price of $\$ 425$ per month. Evaluating the function at this price and the mean

\footnotetext{
${ }^{15}$ In terms of the regression specification, our analysis is most similar to that of Buchmueller (2000). The plan that was the focus of that study had a mean monthly price of $\$ 56.80$ and a mean market share of $51 \%$.
} 
BCMM market share for the full period yields an elasticity of approximately -1.5 . Doing the same calculations using means for all post-1987 retirees gives an insurer-perspective elasticity of $-1.7 .^{16}$

\section{CONCLUSIONS}

This article presents new evidence on the effect of price on the health plan choices of retirees in a managed competition setting. The analysis uses data on Medicare-enrolled retirees from the UM and exploits quasiexperimental price variation caused by the UM's policies governing the premium contributions required of retirees. During the period of our analysis, the premium contribution charged for the most popular plan on the UM menu increased significantly. Because of a prior policy decision, this price increase affected individuals who had retired after a certain date, but not those who had retired before this date. This grandfathering policy creates a sharp discontinuity in prices that effectively divides UM retirees into treatment and control groups according to when they retired. Because the cutoff date was set retroactively, it is not possible that the policy could have affected retirement decisions. We use regression discontinuity methods to analyze this natural experiment.

Although our research design is different than previous studies on the health plan choices of retirees, our results are quite similar. Like prior studies focusing on this population, we find that prices matter for plan choice among Medicare retirees, although the magnitude of the effect is small. At the start of the analysis, most UM retirees were in a major medical plan offered by BCMM in conjunction with United Health Care. Because of its importance in the program and because of the limited degree of price variation in other plans, we model the probability of choosing it relative to any of the others. Descriptive results show that small increases in the cost of the Blue Cross plan relative to others on the menu had no detectable effect on retiree enrollment decisions. However, when the price of this plan increased by roughly $\$ 40$ per month for single coverage and more than $\$ 100$ per month for two-party coverage, there was a significant migration to less expensive plans.

Using dating for the full period, we estimate the average effect of price on the probability of choosing BCMM. Our point estimates imply that, ceteris paribus, a $\$ 10$ increase in premiums leads to a reduction in plan market share of between 2 and 3 percentage points. This marginal effect translates to an insurer-perspective elasticity of between -1 and -2 . These results are similar to those of earlier studies on retirees and smaller in magnitude than price effects estimated for active employees.

Although the finding that the health plan choices of retirees are less sensitive to price than the choices of active employees, the exact reasons for this result are not clear. One possibility may be related to the fact that switching among managed care plans can require changing providers, or at least adapting to new policies regarding referrals and reimbursement. To the extent that they have stronger ties to particular providers, older consumers may be more reluctant than younger consumers to make such changes. However, the fact that research from other countries also finds a negative relationship between age and sensitivity to health insurance premiums suggests that this cannot be the entire answer. ${ }^{17}$

The difference in choice behavior between active employees and retirees may have to do with the ability to make financial decisions and the resources that are available to inform those decisions. To make price-sensitive plan choices, consumers must be able to evaluate trade-offs between monthly premium payments and other financial and nonfinancial aspects of alternative plan options. Such decisions may be difficult for older consumers. Recent studies by Fang et al. (2008) and Levy and Weir (2010) find that cognitive ability is a significant factor influencing whether Medicare beneficiaries purchase supplemental insurance or enroll in Medicare Part D.

\footnotetext{
${ }^{16}$ The insurer-perspective elasticity is slightly higher for the post-1987 retirees for two reasons. One is that because a slightly higher percentage of post-1987 retirees have two-party coverage, the mean BCMM premium for this group is slightly higher than the mean for the full sample (\$438 vs 425). Second, the BCMM market share over the full period is lower for the post-1987 retirees (0.582 vs 0.667$)$.

${ }^{17}$ For example, recent studies using data from Germany and the Netherlands, where consumers can switch insurers without having to switch providers, find that smaller premium elasticities for older consumers compared with younger consumers (Schut et al., 2003; van Djik et al., 2008).
} 
The ability to make good decisions will also depend on the information that is available about choice alternatives. Although in the typical health benefits program active employees and retirees receive similar written materials, employees may have better access to informal sources of information, such as feedback from fellow employees. If cognition and information are important factors affecting retirees' health plan choices, careful consideration should be given to providing retirees information and decision aids that may enhance the response to price. More research on how exactly elderly consumers make health insurance purchase decisions would be valuable.

Because our estimated price effects are based on a comparison of treatment and control groups who faced different prices for the same plans in the same years, we are able to hold constant benefits and other plan characteristics, such as the size and reputation of the provider panel. This is both a strength and a limitation of our analysis. On the positive side, we can be sure that our estimates are not confounded by aspects of plan quality that may be correlated with price. The limitation is that it is not possible with data like ours to say anything about how consumers make trade-offs between premiums and other plan characteristics. Understanding these trade-offs is important in programs like Medicare Part $\mathrm{D}$, where there is considerable variation in nonprice plan attributes.

With any study using data from a single employer, external validity is a concern. Not only is it possible that UM retirees are not representative of all Medicare beneficiaries, but it is important to note that our elasticity estimates are driven mainly by the behavior of a subset of UM retirees, namely, those enrolled in the Blue Cross Blue Shield. The fact that our results are so similar to those of studies using data from other markets reduces but does not eliminate this concern.

If the managed competition approach were applied to Medicare, the effect of such reforms on overall health spending would depend importantly on the strategic behavior of competing health insurers. Another limitation of case studies like the one we analyze is that they are generally not well suited for drawing lessons regarding the supply side of the market. However, such lessons may be gleamed from the health insurance exchanges that will soon be established (and the Massachusetts Connector, which is already in operation) as well as from the market for stand-alone drug coverage under Medicare Part D. Understanding how insurers compete in these new markets is an important goal for future research.

\section{APPENDIX A}

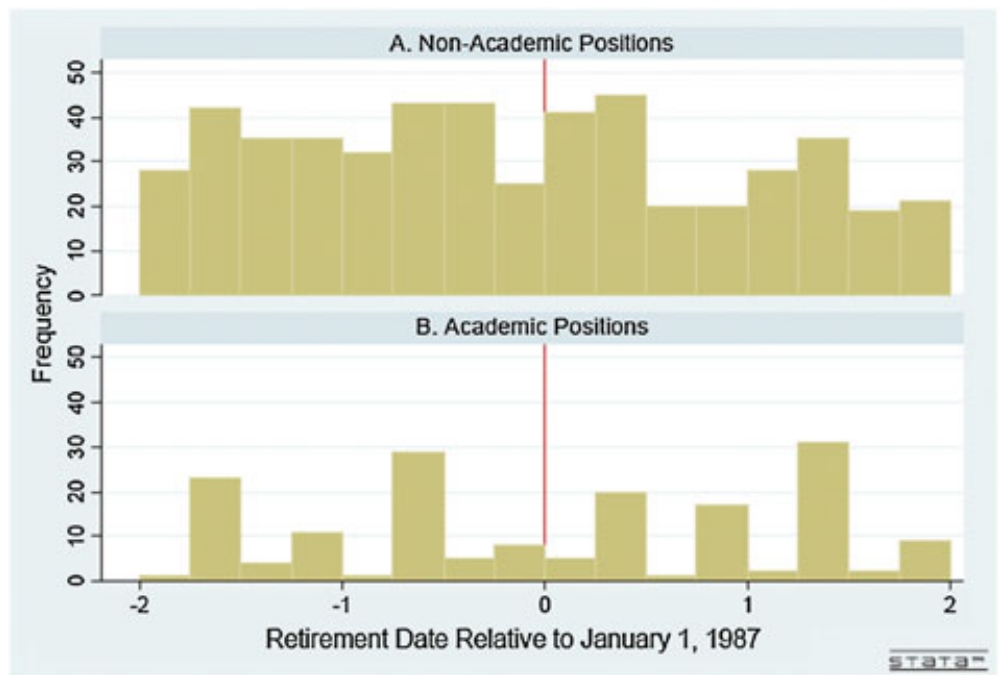

Figure A1. Distribution of retirement dates by quarter relative to January 1987 


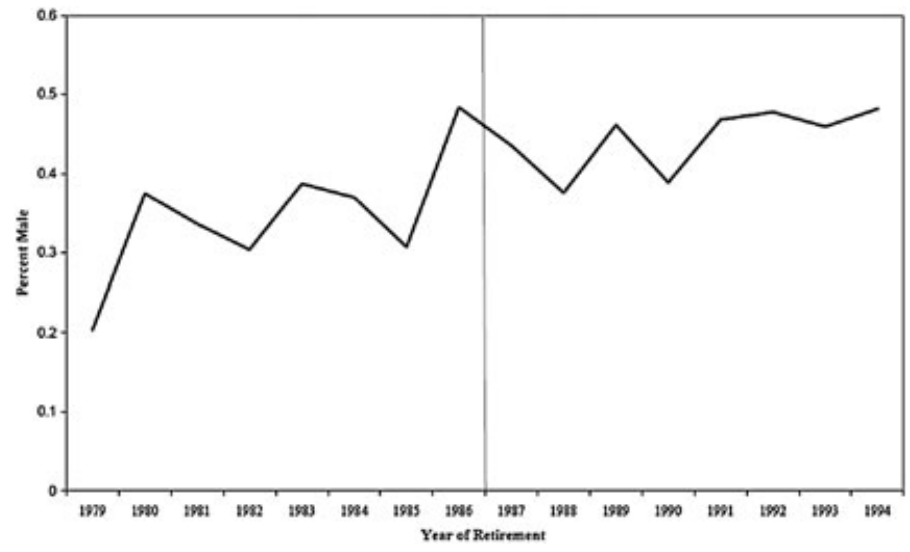

Figure A2. Percentage of male retirees by year of retirement

\section{ACKNOWLEDGEMENTS}

The authors thank the University of Michigan Human Resources office for providing the data used in this study. They specifically acknowledge Marti Eichstadt, Pam Gerber, and Randy Black for their help in understanding the benefits program and the data. They are also indebted to John DiNardo, Guy David, and to participants at the 2010 AcademyHealth Annual Research Meeting and the 2010 Annual Health Economics Conference at Lehigh University for helpful comments and suggestions.

\section{REFERENCES}

Aaron H, Reischauer R. 1995. The Medicare reform debate: what is the next step? Health Affairs 14(4): 8-30.

Buchmueller T. 2000. The health plan choices of retirees under managed competition. Health Services Research 35(5): 949-975.

Buchmueller T. 2006. Price and the health plan choice of retirees. Journal of Health Economics 25(1): 81-101.

Buchmueller T, Feldstein P. 1997. The effect of price on switching among health plans. Journal of Health Economics 16(2): 231-247.

Butler S, Moffit R. 1995. The FEHBP as a model for a new Medicare program. Health Affairs 14(4): 47-61.

Cutler D, Reber S. 1998. Paying for health insurance: the trade off between competition and adverse selection. Quarterly Journal of Economics 113(2): 433-466.

Dowd B, Feldman R. 1994/1995. Premium elasticities of health plan choice. Inquiry 31(4): 438-444.

Dowd B, Feldman R, Christianson J. 1996. Competitive pricing for Medicare. The AEI Press: Washington, DC.

Enthoven A. 1988. Managed competition: an agenda for action. Health Affairs 7(3): 25-47.

Enthoven A. 1993. The history and principles of managed competition. Health Affairs 12(1): 24-48.

Fang H, Keane M, Silverman D. 2008. Sources of advantageous selection: evidence from the Medigap insurance market. Journal of Political Economy 116(2): 303-350.

Feldman R, Finch M, Dowd B, Cassou S. 1989. The demand for employment-based health insurance plans. The Journal of Human Resources 24: 115-142.

Gold M. 2009. Medicare's private plans: a report card on Medicare advantage. Health Affairs 28(2): 597-598.

Kingsdale J. 2010. Health insurance exchanges — key link in a better-value chain. The New England Journal of Medicine 23(362: 2147-2150.

Levy H, Weir D. 2010. Take-up of Medicare Part D: results from the health and retirement study. Journal of Gerontology B: Psychology, Social Science 65B(4): 492-501.

Naessens J, Khan M, Shah N, Wagie A, Pautz R, Campbell C. 2008. Effect of premium, copayments, and health status on the choice of health plans. Medical Care 46(10): 1033-1040. 
Neuman P, Cubanski J. 2009. Medicare Part D update--lessons learned and unfinished business. The New England Journal of Medicine 361(4): 406-414.

Nichols A. 2007. rd: Stata modules for regression discontinuity estimation. (Available from: http://ideas.repec.org/c/boc/ bocode/s456888.html).

Okeke E, Hirth R, Grazier K. 2010a. Workers on the margin: who drops health coverage when prices rise? Inquiry 47(1): 33-47.

Okeke E, Hirth R, Grazier K. 2010b. How much is my partner's health worth? Estimates of the elasticity of spousal coverage. Mimeo, University of Michigan.

Royalty A, Solomon N. 1999. Health plan choice: price elasticities in a managed competition setting. Journal of Human Resources 34(1): 1-41.

Ryan P. 2011. The roadmap plan. (Available from: http://www.roadmap.republicans.budget.house.gov/Plan/, accessed June 17, 2011).

Schut F, Gress S, Wasem J. 2003. Consumer price sensitivity and social health insurer choice in Germany and the Netherlands. International Journal of Health Care Finance and Economics 3(2): 117-138.

Strombom B, Buchmueller T, Feldstein P. 2002. Switching costs, price sensitivity and health plan choice. Journal of Health Economics 21(1): 89-116.

van Djik M, Pomp M, Douven R, Laske-Aldershof T, Schut E, de Boer W, de Boo A. 2008. Consumer price sensitivity in Dutch health insurance. International Journal of Health Care Finance and Economics 8(4): 225-244. 